\title{
TRATAMENTO DE EFLUENTE UTILIZANDO ELETROFLOTAÇÃO: ESTUDO DE CASO PARA REUTILIZAÇÃO DE ÁGUA EM VIVEIRO DE EUCALIPTO.
}

\author{
V. C. de BIASSIO ${ }^{1}$ e J. Sinézio. C. CAMPOS ${ }^{1}$ \\ ${ }^{1}$ Universidade Estadual de Campinas, Faculdade de Engenharia Química, \\ Departamento de Engenharia de Materiais e de Bioprocessos (DEMBio). \\ E-mail para contato: sinezio@,feq.unicamp.br, biassio@,feq.unicamp.br
}

\begin{abstract}
RESUMO - Em vista da diminuição dos recursos hídricos muitos pesquisadores tem investido tempo na melhoria ou criação de novos processos de tratamento no sentido de se aproveitar (reuso) ao máximo os efluentes. Dentre a grande diversidade de efluentes o presente trabalho volta sua atenção para os oriundos de viveiros de eucaliptos. Em geral, tais efluentes são ricos em sais, porém contêm alto teor de sólidos suspensos, dificultando assim sua reutilização no processo. Visando a remoção de sólidos suspensos, o presente trabalho apresenta resultados obtidos no tratamento de efluente de viveiro de eucalipto utilizando a técnica de eletroflotação, técnica esta investigada pelo grupo Física de Polímeros (FisPol) da UNICAMP, a qual utilizada em outros efluentes surtiram excelentes resultados. O reator é composto por uma cuba (40 litros), eletrodos de alumínio (4 pares de placas, área de $140 \mathrm{~cm}^{2} /$ placa) e fonte de tensão contínua com controle de corrente elétrica. Os resultados indicam redução em $70 \%$ a DBO, $81 \%$ a DQO e $94 \%$ a turbidez, sendo que o tempo de tratamento é em geral ao redor de 60 minutos. Tempo este relativamente baixo em comparação com outros processos; indicando que o processo de eletroflotação é promissor no tratamento e potencial reuso de tais efluentes.
\end{abstract}

\section{INTRODUÇÃO}

A eletroflotação é uma técnica conhecida desde 1870 e, segundo a CETESB (1988), foi utilizada primeiramente para tratar esgoto doméstico; mas hoje em dia é relativamente baixo o seu uso industrial. Entretanto, observa-se aumento do interesse em tal técnica, principalmente o interesse científico, em aprimorá-la em ramos da indústria de alimentos, papéis, petrolíferas, metalúrgicas e têxteis, como é evidente nos trabalhos publicados de Ferreira (2006), Camboim (2010), Oliveira (2012), Stülp et al (2005), Crespilho et al (2004) e outros.

O tratamento de efluentes, tanto para descarte quanto para reutilização, é realizado pelas diversas indústrias, as quais avaliam as características de seus efluentes e decidem o método que atende às suas necessidades e às legislações vigentes, como a Resolução CONAMA n³57 (2005). Devido ao período de estiagem prolongado dos últimos anos, o estado de São Paulo está passando por uma grande crise hídrica e a solução para as empresas é reutilizar totalmente ou pelo menos grande parte de seus efluentes. 
Entre essas empresas está a produtora de mudas de eucalipto, com grande consumo de água tanto para processo quanto para irrigação. Em especial na parte da irrigação, que reutiliza água do processo, observou-se acúmulo de sólidos suspensos sobre as folhas das mudas, provocando uma diminuição da área de fotossíntese, consequentemente prejudicando o crescimento das mudas. Com o objetivo de minimizar este problema ocasionado pela elevada concentração de sólidos suspensos, avaliou-se vários tipos de tratamento e dentre estes optou-se pelo processo de eletroflotação em decorrência das características de condutividade elétrica do efluente.

Durante o processo de eletroflotação, utilizando-se eletrodos de alumínio, são gerados elementos coagulantes e gases de acordo com as reações $(1,2,3$, e 4) básicas descritas a seguir.

Oxidação do Al sólido (reação anódica)

$$
A l \rightarrow A l_{(a q)}^{3+}+3 e^{-}
$$

Solvatação do cátion (reação catódica)

$$
\mathrm{Al}^{3+}{ }_{(a q)}+6 \mathrm{H}_{2} \mathrm{O} \rightarrow \mathrm{Al}\left(\mathrm{H}_{2} \mathrm{O}\right)_{6}^{3+}
$$

Formação de agente coagulante

$$
\mathrm{Al}\left(\mathrm{H}_{2} \mathrm{O}\right)_{6}^{3+} \rightarrow \mathrm{Al}(\mathrm{OH})_{3(s)}+3 \mathrm{H}^{+}+3 \mathrm{H}_{2} \mathrm{O}
$$

Reações Secundárias

$$
n \mathrm{Al}(\mathrm{OH})_{3} \rightarrow \mathrm{Al}_{n}(\mathrm{OH})_{3 n(s)}
$$

Como o coagulante é gerado durante o tratamento, o processo de eletroflotação não utiliza adição de produtos químicos e por isso é considerado um processo mais benéfico ao meio ambiente. Este processo também tem a vantagem de utilizar pouco espaço, ter alta eficiência energética, versatilidade e equipamentos de fácil operação. (Crespilho et al, 2004).

Uma das características mais almejadas desse processo é a capacidade de remoção de partículas coloidais menores, comuns em efluentes que contém óleos e graxas, tal característica o torna um método bastante utilizado em petrolíferas e metalúrgicas (Oliveira, 2012).

\section{MATERIAIS E MÉTODOS}

Utilizaram-se para o tratamento amostras de efluente de viveiro de eucalipto coletadas diretamente dos tanques de armazenamento, como mostra a Figura 1.

O efluente foi coletado no dia anterior e permaneceu em embalagem fechada até o tratamento. Realizaram-se tratamentos em diferentes épocas do ano, com o objetivo de avaliar os resultados de acordo com a composição do efluente, a qual varia de acordo com o índice pluviométrico e temperatura. 


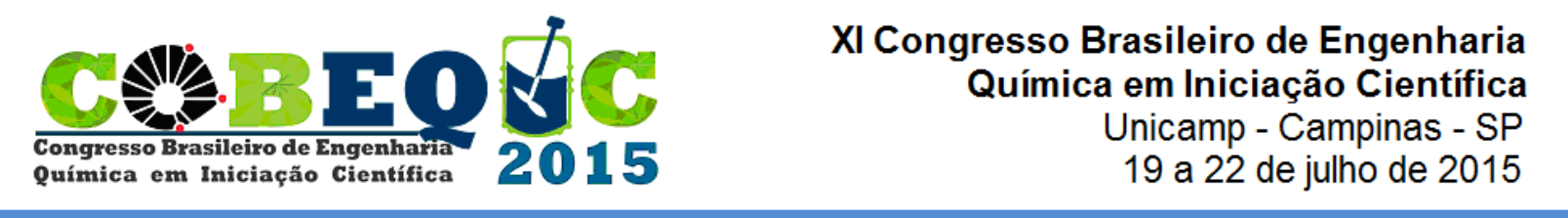

Figura 1 - Tanque de armazenamento para efluente de reuso.

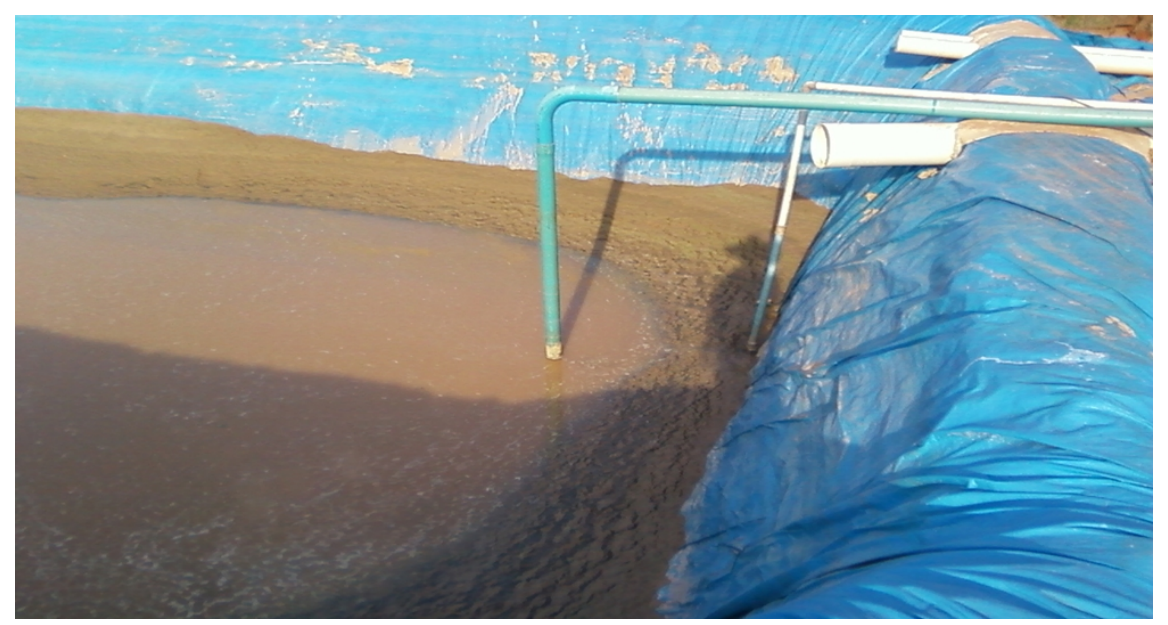

O reator (cuba, fonte de tensão, controlador de corrente elétrica, eletrodo de alumínio (área de cada placa de $\left.140 \mathrm{~cm}^{2}\right)$ ) construído pelo Prof. Sinézio, coordenador do Laboratório de Física de Polímeros (FisPol), pertencente ao DEMBio/FEQ/UNICAMP, tem cuba com capacidade máxima para 40 litros, fonte de tensão com controlador de corrente e amperímetro para medida da corrente elétrica no processo. Tal reator pode ser visualizado na Figura 2. Em particular a fonte de tensão é uma fonte de computador, modificada para fornecer tensão fixa e corrente de até 30 ampéres.

A partir de 25 minutos o efluente torna-se límpido o suficiente para visualização dos eletrodos de alumínio no interior da cuba. Ressalta-se que a duração do tempo de tratamento é de aproximadamente 60 minutos.

Figura 2 - Reator contendo o efluente para início do tratamento (a) e (b) no final do tratamento.

a)

b)

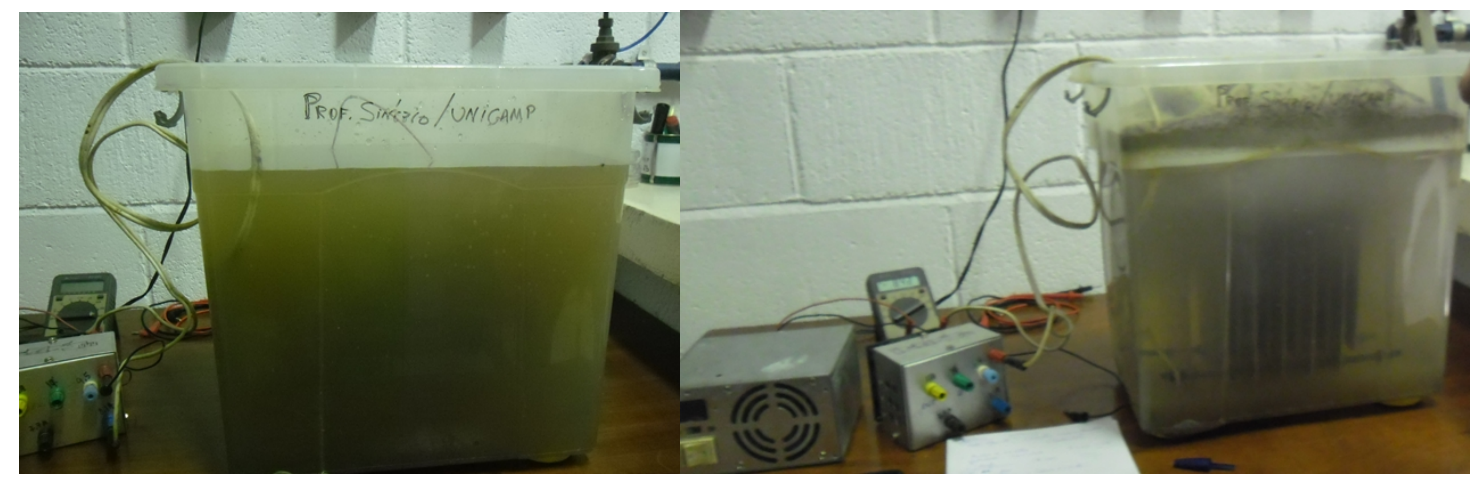

Caracterizaram-se os efluentes antes e após o tratamento quanto aos seguintes parâmetros: $\mathrm{pH}$, temperatura, condutividade, turbidez, $\mathrm{DQO}$ e $\mathrm{DBO}$, sendo estes quantificados no início e no final do tratamento e os resultados são apresentados na Tabela 1. 


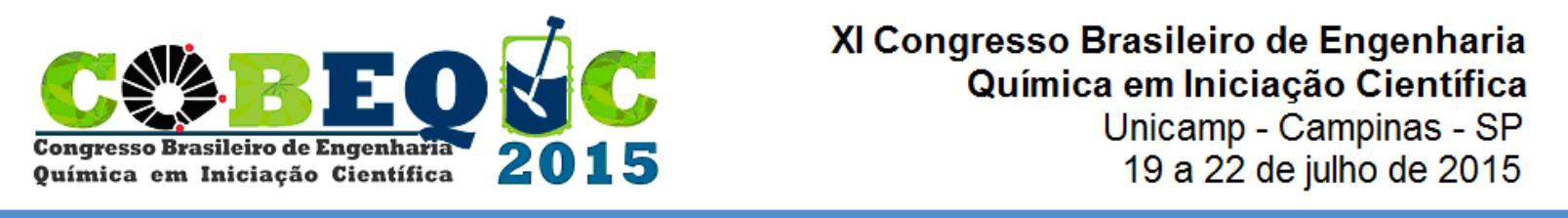

Tabela 1 - Resultados dos parâmetros analisados.

\begin{tabular}{ccc}
\hline Parâmetro & \multicolumn{2}{c}{ Resultados } \\
Analisado & Inicial & Final \\
\hline $\mathrm{pH}$ & 7,5 & 9,4 \\
Temperatura $\left({ }^{\circ} \mathrm{C}\right)$ & 23 & 28 \\
Condutividade $\left(\mu \mathrm{S} / \mathrm{cm}^{2}\right)$ & 1015,7 & 854 \\
Turbidez $(\mathrm{NTU})_{\mathrm{DBO}_{5}\left(\mathrm{mg} \mathrm{O}_{2} / \mathrm{L}\right)}^{282,3}$ & 18,8 \\
$\mathrm{DQO}_{\left(\mathrm{mg} \mathrm{O}_{2} / \mathrm{L}\right)}$ & 12,4 & 3,8 \\
\hline
\end{tabular}

É possível verificar a remoção de sólidos suspensos visualmente, comparando-se as imagens na Figura 3 para o efluente antes (à esquerda) e após (à direita) tratamento por eletroflotação.

Figura 3 - Amostras do efluente antes (à esquerda) e após (à direita) tratamento por eletroflotação.

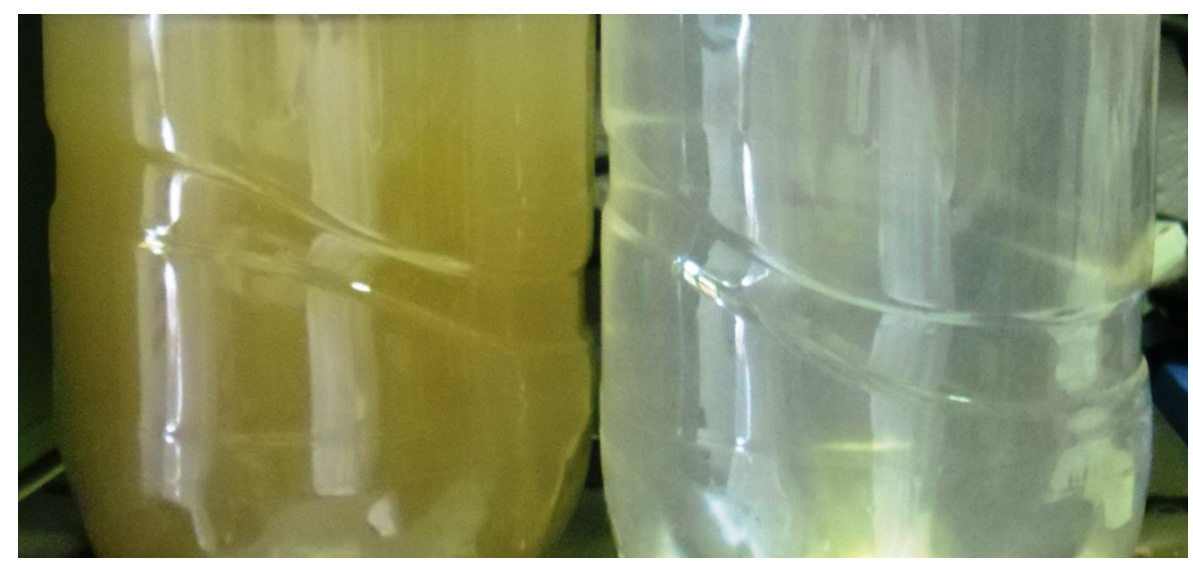

\section{RESULTADOS E DISCUSSÃO}

Os resultados apresentados na Tabela 1 mostram que o tratamento é eficiente, reduzindo a DBO em $70 \%$ a DQO em $81 \%$ e a turbidez em $94 \%$. Em vista dos resultados obtidos, observando os parâmetros e normas ambientais, o efluente tornou-se apropriado para ser reutilizado para irrigação, principalmente pela grande redução da turbidez.

Observou-se elevação no valor de $\mathrm{pH}$ (início=7,5 e final $=9,4$ ) durante o tratamento devido à liberação de íons hidroxila gerados pelas reações eletrolíticas. $\mathrm{O}$ aumento na temperatura ocasionado pela conversão da energia elétrica em calor, conhecido como efeito Joule, pode ser considerado pequeno e, no entanto benéfico como observado por outros pesquisadores. 


\section{CONCLUSÃO}

De acordo com os resultados obtidos o tratamento do efluente utilizando a eletroflotação se mostrou adequado, pois atende à necessidade de redução de turbidez, além de reduzir a DBO e DQO. Um fator muito importante e que revela a viabilidade econômica do tratamento foi o curto tempo necessário para remoção dos contaminantes, visto que quanto maior o tempo necessário para tratar um efluente maior será o gasto com eletricidade e com o consumo de eletrodo. O resíduo flotado está sendo analisado para possível utilização como fertilizante.

\section{AGRADECIMENTOS}

À empresa Brotale Florestal pelo material (efluente) cedido para pesquisa.

Ao Laboratório de Saneamento da Faculdade de Engenharia Civil da UNICAMP pela realização das análises e disponibilização de equipamentos.

\section{NOMENCLATURA}

DBO: Demanda Bioquímica por oxigênio

DQO: Demanda Química por oxigênio

FisPol: Física de Polímeros

pH: potencial hidrogeniônico

UNICAMP: Universidade Estadual de Campinas

\section{REFERÊNCIAS}

CAMBOIM, R. A. Técnica de eletroflotação aplicada na remoção de cores de efluentes têxteis. Dissertação de mestrado. UNICAMP, 2010.

CETESB. Diagnóstico da situação atual das estações eletrolíticas de tratamento de esgoto. São Paulo. CETESB, 1988.

CONAMA. Resolução CONAMA no 357 de 2005. CONAMA, 2005.

CRESPILHO, F. N. REZENDE, M. O. Eletroflotação: Princípios e Aplicações. São Carlos. Ed. Rima, 2004, p.85. 
FERREIRA, L. H. Remoção de sólidos em suspensão de efluente da indústria de papel por eletroflotação. Dissertação de mestrado. UNICAMP, 2006.

OLIVEIRA, J. S. de. Tratamento da água produzida utilizando a eletroflotação e o processo combinado eletroflotação/fenton em reator de reciclo fechado. Dissertação de mestrado. UNIT, 2010.

STÜLP, S. SILVA, C. P. MARMITT, S. O uso de técnicas eletroquímicas no tratamento de efluentes de indústria alimentícia: Uma ferramenta para gestão ambiental. Estudo \& Debate, Lageado, 2005. v.12, n.2, p.109-123. 